\title{
O TENSIONAMENTO ENTRE ESTADO E ECONOMIA NO CONTEXTO DO CONSTITUCIONALISMO DEMOCRÁTICO: ANÁLISE DA FUNÇÃO REGULATÓRIA E O ATUAL ESTÁGIO JURÍDICO E ECONÔMICO DO BRASIL
}

\author{
TENSIONING BETWEEN STATE AND ECONOMY IN THE CONTEXT OF \\ DEMOCRATIC CONSTITUTIONALISM: ANALYSIS OF THE REGULATORY FUNCTION \\ AND THE CURRENT LEGAL AND ECONOMIC STAGE IN BRAZIL
}

Fabrício Macedo Motta

Possui Graduação em Direito pela Universidade Federal de Goiás (1998), Mestrado em Direito Administrativo pela Universidade Federal de Minas Gerais (2002) e Doutorado em Direito do Estado pela Universidade de São Paulo (2007). Atualmente, é Conselheiro do Tribunal de Contas dos Municípios do Estado de Goiás, tendo sido Procurador do Ministério Público de Contas, e Professor Adjunto da Universidade Federal de Goiás. É Vice-Coordenador do Programa de Mestrado Profissional em Direito e Políticas Públicas, na Faculdade de Direito da UFG. É Presidente do Instituto Brasileiro de Direito Administrativo (2017-2020).

\section{Leonardo Buissa Freitas}

Doutor em Direito Econômico, Financeiro e Tributário pela Faculdade de Direito da Universidade de São Paulo (USP). Mestre em Direito pela Universidade Federal de Goiás (UFG). Especialista em Direito Processual Civil pela UFG. Professor Adjunto da Faculdade de Direito da Universidade Federal de Goiás. Professor do Quadro Permanente do Mestrado Profissional em Direito e Políticas Públicas na Universidade Federal de Goiás. Professor da Escola Superior da Magistratura do Estado de Goiás.

Mateus Rocha de Lisbôa

Possui graduação em Direito pela Universidade Federal de Goiás (2018). Mestrando em Direito e Políticas Públicas pela Universidade Federal de Goiás. Pós-graduando em Direito Tributário pela Universidade de São Paulo. Atualmente é advogado - Pimentel Kirian e Castro Advogados. Tem experiência na área de Direito, com ênfase em Direito Público, especialmente na área de Direito Tributário.

\section{Resumo}

O presente estudo abordará a atividade regulatória exercida pelo Estado, a qual ganhou destaque no Brasil a partir dos anos de 1990 
com o surgimento das agências reguladoras. Dessa forma, busca-se compreender a relação entre Estado e economia no contexto do Constitucionalismo Democrático a partir de uma perspectiva da regulação. Para tanto, serão analisados seus antecedentes históricos, os fundamentos teóricos que proporcionaram seu surgimento e sua consolidação e o atual estágio político e econômico brasileiro, destacando-se a tentativa de estabelecimento de limitações à atividade regulatória. Nesse sentido, será empreendido estudo da Análise de Impacto Regulatório, instrumento lançado com intuito de racionalizar os efeitos da regulação. Através desse percurso, tornou-se possível compreender, no âmbito da atividade regulatória, o tensionamento existente entre Estado e economia no contexto do Constitucionalismo Democrático.

Palavras-chave: Regulação. Constitucionalismo Democrático. Análise de Impacto Regulatório.

\begin{abstract}
This study will address the regulatory activity exercised by the State, which gained prominence in Brazil from the 1990s onwards with the emergence of regulatory agencies. Thus, it seeks to understand the relationship between the State and the economy in the context of Democratic Constitutionalism from a regulatory perspective. To this end, its historical background, the theoretical foundations that provided for its emergence and consolidation, and the current Brazilian political and economic stage will be analyzed, with emphasis on the attempt to establish limitations to regulatory activity. In this sense, a study of the Regulatory Impact Analysis will be undertaken, an instrument launched in order to rationalize the effects of regulation. Through this path, it became possible to understand, within the scope of regulatory activity, the tension between State and economy in the context of Democratic Constitutionalism.
\end{abstract}

Key-words: Regulation. Democratic Constitutionalism. Regulatory Impact Analysis.

\title{
1. CONSIDERAÇÕES INICIAIS
}

O presente artigo concentrar-se-á na análise do exercício da atividade regulatória pelo Estado brasileiro, compreendendo seus antecedentes históricos e sua implementação no país. Constatado o Direito Regulatório em vigência no ordenamento jurídico pátrio, será analisado o atual cenário político e econômico vivenciado no Brasil, com destaque para as ideias neoliberais e as tentativas de limitações do exercício da atividade regulatória, empreendendo estudo da Análise de Impacto Regulatório (AIR), mecanismo que visa sopesar os efeitos da atividade regulatória sobre determinados campos de atuação. Dessa forma, compreende-se ser possível concluir, ao final, a maneira como se deve processar a atividade regulatória no contexto do Constitucionalismo Democrático. 
Assim sendo, o estudo ora empreendido será voltado para análise histórica e jurídica da atividade regulatória no Brasil, compreendendo o arcabouço normativo no qual está inserido e as influências sobre as áreas objeto de regulação, bem como as próprias influências externas sofridas pelos agentes regulatórios, em especial as advindas do campo político e econômico.

Nesse sentido, manifesta-se como objetivo principal desta pesquisa a compreensão da regulação no atual estágio jurídico e econômico do Brasil, enquanto mecanismo oriundo do tensionamento entre Estado e economia no contexto do Constitucionalismo Democrático.

Ademais, apresentam-se também como objetivos específicos deste artigo a análise dos antecedentes históricos que contribuíram para o surgimento da atividade regulatória no Estado brasileiro, em especial a partir da década de 1990, com o surgimento das agências reguladoras no contexto das privatizações realizadas na reforma administrativa do Estado durante o governo Fernando Henrique Cardoso.

Além disso, a devida compreensão da atividade regulatória no Brasil emerge como segundo objetivo específico do presente estudo, buscando constatar em que consiste o Direito Regulatório, seu campo de atuação e suas limitações previstas no ordenamento jurídico pátrio, bem como as influências sofridas pelo setor político e econômico sobre as agências reguladoras.

Ainda, como terceiro objetivo específico, indica-se a observação do incurso neoliberal sobre o Direito Regulatório brasileiro, empreendendo observações a respeito da Análise de Impacto Regulatório enquanto mecanismo que visa racionalizar e aferir os efeitos advindos da atividade regulatória exercida pelas agências competentes.

Para a concretização das propostas levantadas, empreender-se-á revisão de literatura para compreensão dos conceitos atinentes à atividade regulatória, seus antecedentes históricos e sua limitação e delineamento normativo realizado pelo ordenamento jurídico. Por fim, utilizar-se-á estudo de caso para constatar a natureza da Análise de Impacto Regulatório e seus efeitos sobre o Direito Regulatório.

Dessa maneira, compreende-se de fundamental importância o estudo a respeito do objeto do presente artigo, tendo em vista as possíveis mudanças a serem enfrentadas pelo Direito Regulatório no Brasil no atual cenário político e econômico.

\section{ANTECEDENTES HISTÓRICOS DA ATIVIDADE REGULATÓRIA}


As mudanças sociais vivenciadas a partir do século $X V$, em especial no continente europeu, a partir da concentração do poder nas mãos do Monarca, em detrimento dos diversos e esparsos centros locais de poder que caracterizaram o período medieval, fizeram surgir o que se tem conceituado como Estado Absolutista.

Nesse período histórico emerge configuração estatal na qual se destacam a busca de consolidação da ideia de soberania, a partir da concentração progressiva de poder em mãos do monarca e do desenvolvimento de atividades tidas como essencialmente estatais, como o uso da força, o privilégio de emitir moeda e o de arrecadar impostos (CHEVALLIER, 2009, p. 61).

A partir das revoluções burguesas, consolida-se o Estado Moderno, voltado, primordialmente, à garantia das liberdades dos cidadãos frente ao Estado Absolutista. No aspecto econômico (Estado Liberal), isso revela-se com a ampla abertura conferida aos cidadãos, diminuindo a interferência estatal, tendo em vista que o fortalecimento do Estado Nacional já fora consolidado anteriormente (MARQUES NETO, 2002, p. 102), desnecessitando de sua atuação como elo essencial na estruturação da cadeia produtiva.

Ocorre que ao longo do século XX, em especial após a Primeira Guerra Mundial, o sistema capitalista volta a necessitar de grandes somas de capital para o novo estágio de desenvolvimento que se iniciava (MARQUES NETO, 2002, p. 101), retomando assim período de grande intervenção estatal na economia.

Desse contexto que dominou o século passado emerge novo caminho em sentido contrário, em especial em suas três décadas finais, quando a relação dialética entre Estado e economia retoma uma perspectiva de menor intervenção por parte do agente estatal, sem, contudo, se afastar por completo da atuação dos entes privados na seara econômica. Será nesse contexto que a atividade regulatória surgirá e se consolidará.

\section{A REGULAÇÃO NO BRASIL}

A regulação no Brasil inicia-se de forma institucionalizada a partir da década de 90, com a reforma administrativa do Estado, garantindo maior autonomia à atuação das agências que foram sendo criadas sob a qualificação de reguladoras. Para a devida compreensão desse fenômeno, cabe delinear o avanço dessa temática por 
meio da análise dos textos constitucionais anteriores à Carta de 1988.

Assim, na Constituição de 1824 inexistiu qualquer previsão a respeito da intervenção estatal na esfera econômica, sendo apenas na de 1934 que inicia-se a preocupação com a ordem econômica e social (artigos 115 a 143). Todavia, o primeiro texto constitucional a ter dispositivos a respeito da intervenção no setor econômico foi o de 1937, passando a disciplinar tal possibilidade nas hipóteses de suprimento de deficiências da iniciativa individual e de coordenação dos fatores de produção (BOCKMANN, 2014, p. 120).

Nas Constituições de 1946 e 1967, a intervenção do Estado na economia passa a ser faculdade do Poder Público, a ser estabelecida por lei específica e tendo como fundamento interesse público, indispensável motivo de segurança nacional ou quando inexistisse possibilidade de desenvolvimento eficaz no regime de competição e de liberdade de iniciativa.

Com a outorga da Emenda Constitucional 1/1969, emerge pela primeira vez no ordenamento jurídico pátrio dispositivo de ordem constitucional prevendo o propósito específico do planejamento estatal na economia (BOCKMANN, 2014, p. 121 e 122). Cabe ponderar que, de fato, diversos planos econômicos foram instituídos nos governos anteriores, podendo ser citados o Plano de Metas do governo Juscelino e o Plano Salte do governo Dutra. No entanto, apenas com a EC 1/1969 tal assunto se tornou objeto de Direito Constitucional.

$\mathrm{Na}$ prática, as consequências dessas estruturas jurídico-constitucionais refletiam diretamente na interação entre Estado e economia, tendo em vista que a atuação daquele se dava apenas por meio de regulamentos de execução às leis, dando-Ihes aplicabilidade prática.

Essa perspectiva se perpetuou inclusive no texto constitucional de 1988, o qual, por meio do artigo 84, IV, restringia a expedição de decretos e regulamentos para a fiel execução de leis. Somente com as Emendas Constitucionais n. 8 e 9 de 1995, instituidoras da reforma administrativa do Estado brasileiro, é que passou a existir no texto constitucional previsão de "órgão" ou "entidade" reguladora da economia (BOCKAMANN, 2014, p. 120).

Nesse sentido, constata-se que a relação entre Estado e economia no período anterior à institucionalização das agências reguladoras na década de 1990 se processava pelo binômio "poder de polícia" - "serviço público", além da própria atuação direta na economia, por meio do exercício de atividade empresarial no domínio privado 
(BOCKMANN, 2014, p. 108).

A menor complexidade da relação entre Estado e economia decorria da estanque e pouco dinâmica estrutura desenvolvida para tanto. Assim, diante da inexistência da atividade regulatória, a intervenção indireta do Estado sobre os agentes privados somente se dava por meio do exercício do poder de polícia (BOCKMANN, 2014, p. 108) - “(...) o direito da regulação era subsumido ao gênero 'poder de polícia administrativa'”.

Acerca dos serviços públicos, deve-se pontuar que a Constituição Federal e as Emendas Constitucionais de 1995, promotoras da referida reforma administrativa do Estado brasileiro, constata-se notória transformação por parte da atuação estatal nacional: o afastamento da gestão direta da atividade produtiva e a abertura desse campo à iniciativa privada, bem como a possibilidade de atuação estrangeira (SALGADO, 2003, p. 21).

Assim sendo, consagra-se a autonomia da regulação, desprendendo-se da concepção inserida no gênero "poder de polícia" e empreendendo mudança no tensionamento entre Estado e economia: com a relação permeada de características mais democráticas, estimuladoras, cooperativas e substitutivas, altera-se a lógica do "Estado ou-ou iniciativa privada" para a de "Estado e-e iniciativa privada" (BOCKMANN, 2014, p. 112).

Para Caio Mário Neto (PEREIRA NETO, LANCIERI e ADAMI, 2014, p. 144), a institucionalização da regulação no Brasil marca a alteração de perfil da atividade estatal: o distanciamento do modelo patrimonialista, marcado pela intensa participação direta do Estado na economia, e a implementação de um modelo gerencial, com quatro objetivos primordiais a serem alcançados: (i) implementação de uma nova relação entre Estado e economia, em um ambiente mais aberto e com expressiva participação da iniciativa privada; (ii) introdução de competição em setores antes monopolizados pelo Estado; (iii) garantia da universalização de serviços públicos essenciais; e (iv) contribuição para uma reforma gerencial da Administração Pública, pautada nos valores de eficiência e qualidade na prestação dos serviços públicos.

Ante o exposto, pode-se compreender a regulação como conjunto de ações jurídicas voltadas ao estabelecimento de parâmetros de conduta econômica em determinado espaço-tempo. Nesse sentido, pode-se realizar cinco recortes metodológicos para análise e compreensão da regulação: (i) técnicas regulamentares, (ii) sujeitos, (iii) fontes, (iv) objeto e (v) intensidade (BOCKMANN, 2014, p. 112). 
Acerca das técnicas regulamentares, o agente regulador poderá atuar pautado na gestão, a partir de sua inserção no setor econômico por meio de empresa, ou na normatividade, quando o agente editará normas que adentrarão no mundo do deverser dos agentes privados. Assim, com relação aos sujeitos que poderão exercer a atividade regulatória, pode-se citar os agentes públicos: entidades ou órgãos da Administração Pública (heterorregulação) e os agentes privados: associações privadas e público-privadas, tais como a OAB e o CFM.

A respeito das fontes, com a institucionalização da regulação no Direito brasileiro, constata-se a multiplicidade de fontes normativas, passando a consistir como complexo constituído pelos dispositivos estatuídos pela Constituição Federal, por leis, regulamentos administrativos, códigos de condutas e boas práticas e contratos.

Ainda, acerca do objeto das normas regulatórias, pode-se realizar a análise metodológica sobre quatro perspectivas: (i) funcionamento da Administração Pública, (ii) comportamento econômico de pessoas de direito privado, (iii) comportamento ético dos envolvidos, e (iv) parâmetros técnicos.

Por fim, com relação ao grau de intensidade da atividade regulatória, esta poderá ser observada através de incentivos, estímulos e sanções positivas (regulação soft) e por meio do estabelecimento de ordens, proibições e obrigações (regulação hard).

Conforme discorre Sérgio Guerra (GUERRA, 2013, p. 233), o modelo de escolha regulatória adotado no Brasil implica, do ponto de vista jurídico, na regulação estatal sob a ótica da organização administrativa, com medidas setoriais / sistêmicas, emergindo, assim, especialização dos ramos do direito no sistema jurídico. Assim, o fundamento da atuação estatal na economia passa a ser pautada na adequação, necessidade e proporcionalidade para o equilíbrio dos subsistemas.

Operacionalizando juridicamente todo esse arcabouço teórico, surgem como mecanismos legais (GUERRA, 2013, p. 234 a 236): (i) regulação direta por meio de Ministérios e Secretarias; (ii) regulação estatal via autarquias; (iii) Agências Executivas (ex. INMETRO); (iv) autarquias especiais - Agências Reguladoras, Comissão de Valores Mobiliários e o CADE; (v) conselhos profissionais; (vi) autorregulação exercida pela OAB.

Para Egon Bockmann (BOCKMANN, 2013, p. 113), o fenômeno jurídico da regulação no Brasil pode ser encarado, em nível constitucional (artigos 173 e 174, CF), 
por meio de quatro atividades principais: (i) gestão pública de atividades econômicas (empresas estatais); (ii) edição de normas jurídicas que visem a conformar a conduta dos agentes econômicos (incentivos); (iii) direito da ordenação social (disciplina, fiscalização e punição); (iv) planejamento estatal.

Ainda na esfera constitucional, ressaltam-se as Emendas Constitucionais $\mathrm{n}$. 8/1995 e 9/1995, instituidoras, respectivamente, do órgão regulador de telecomunicações e do monopólio no setor de petróleo. Já em nível infraconstitucional, podem-se citar as diversas leis prevendo a criação de novas agências reguladoras: ANEEL, ANATEL, ANP, ANS, ANA, ANTT, ANTAQ, ANCINE e ANAC.

A respeito da compreensão jusprincipiológica dos entes regulatórios (SALGADO, 2003, p. 24), destacam-se a autonomia e independência decisória; ampla publicidade de normas, procedimentos e ações; celeridade processual e simplificação das relações entre consumidores e investidores; participação de todas as partes interessadas no processo de elaboração de normas regulamentares, em audiências públicas; e limitação da intervenção estatal na prestação de serviços públicos, aos níveis indispensáveis à sua execução.

Compreendido o substrato jurídico da regulação no Brasil, constata-se notória a alteração do sentido clássico de determinados princípios jurídicos do Direito Administrativo. O primeiro deles remonta à visão clássica da legalidade, a qual, sofrendo mutação constitucional (BOCKMANN e CAGGIANO, 2013), passa a ser empreendida como necessidade de atendimento ao ordenamento jurídico como um todo, o que possibilita a atuação normativa por parte das agências reguladoras.

O princípio da supremacia do interesse público também pode ser constatado (MARQUES NETO, 2009, p. 85 e 86), diante da ampliação da atuação estatal na economia, não se restringindo apenas à intervenção direta por meio de empresas públicas, mas também por meio da regulação. Assim, o interesse público passa a não ser mais o interesse do Estado, mas sim com o interesse da coletividade.

Por fim, o princípio da separação dos poderes também sofre mudanças nesse contexto (GRAU, 2011, p. 182). Isso porque a função normativa também passa a ser exercida de maneira mais acentuada por entes vinculados ao Poder Executivo, nos casos, as agências reguladoras, não estando mais restringida tal função ao Poder Legislativo.

Nessa perspectiva de alterações atinentes às relações entre os Poderes instituídos, cabível se torna a análise do diálogo institucional entre agências 
reguladoras com os Poderes Executivo, Legislativo e Judiciário a partir da consolidação da regulação no Brasil (PEREIRA NETO, LANCIERI e ADAMI, 2014, p. 150).

Nesse cenário, a respeito do diálogo institucional entre tais agências e Executivo, deve-se preservar a maior independência e autonomia para aquelas, de forma a se evitar as ingerências e a captura política. Com relação ao Poder Legislativo, o diálogo institucional deverá se processar com respeito à definição de competências atribuídas às agências reguladoras nas respectivas leis de criação. Por fim, junto ao Judiciário, devem-se destacar dois aspectos referentes ao diálogo institucional: (i) a atuação desse Poder como árbitro da relação litigiosa entre agências reguladoras e demais atores institucionais e (ii) a definição da própria moldura da atividade regulatória, conferindo amplo espaço decisória para sua atuação, em homenagem à deferência a essas autarquias.

Em síntese, a atividade regulatória no Brasil deve ser encarada como modelo adotado pelo país a partir da década de 1990, diante do aumento de complexidade na relação entre Estado e economia, possibilitando a atuação direta por agentes privados, tendo o ente estatal atuação indireta por meio da regulação, estabelecendo normas sobre o domínio privado, por meio de agências reguladoras, autarquias dotadas de autonomia estrutural e normativa.

\section{O INCURSO NEOLIBERAL E AS TENTATIVAS DE LIMITAÇÃO DE ATIVIDADE REGULATÓRIA - ESTUDO DA ANÁLISE DE IMPACTO REGULATÓRIO}

Compreendido o arcabouço fático, teórico e jurídico que possibilitou a institucionalização da regulação no país a partir da década de 1990, devem ser apontadas por ora os percalços por ela experimentada, de modo que se possa compreender não apenas seus limites de atuação e as mudanças necessárias a serem tomadas, mas também, prioritariamente, constatar a relevância da regulação no atual cenário jurídico e político brasileiro.

Dessa forma, analisando as problemáticas envolvendo a heterorregulação desenvolvida pelas agências reguladoras, Egon Bockmann (BOCKMANN, 2014, p. 132 e 133) indica que a maior dificuldade para se assegurar a independência e a autonomia dessas autarquias encontra-se na preservação de sua sanidade mental e 
integridade física.

A respeito da integridade mental, a carência de cérebros e de corpo técnico especializado, bem como a lógica de nomeação fundada em critérios políticogovernamentais ocasiona grave problema na atuação das agências. Além disso, a migração pública, caracterizada pela indevida normatividade conferida à quarentena, permitindo com que dirigentes das agências migrem para cargos políticos ou para outras agências, fere frontalmente a necessidade de tecnicidade por parte desses órgãos.

Ainda, cabe destacar o locaute regulatório (ausência de dirigentes nas agências, quando estas ficam ocupadas por meros "interinos" ou sem diretor com elevado conhecimento técnico) e a inanição regulatória, instalada na ocorrência de ausência de repasses de verbas necessárias às agências reguladoras para 0 cumprimento de suas tarefas. Por fim, a captura bifronte, que pode ocorrer tanto pelo Estado, por questão políticas, como pelo mercado, também manifesta-se como problemática a ser combatida na estruturação das agências reguladoras.

Todas essas questões supra levantadas consistem embates internos a serem tratados no âmbito de atuação dessas agências. Externamente, a regulação vem sendo criticada pelos supostos efeitos deletérios que trazem para a livre iniciativa, no sentido de interferência sobre a liberdade econômica, consistindo em maiores custos na atuação do domínio privado.

Tal perspectiva pode ser compreendida a partir da Lei da Liberdade Econômica (Lei Federal n. 13.874/2019), fruto de propostas de desregulação da economia brasileira, fundamentando-se, conforme se extrai de sua exposição de motivos, na busca por conceder "direitos aos brasileiro contra um Estado irracionalmente controlador".

Assim, constata-se que o tensionamento entre Estado e economia no atual cenário de incursos neoliberais apresenta nova faceta, no sentido de se buscar diminuir ou afastar a atuação regulatória por parte do Estado. Esse, todavia, não deve ser o caminho a ser seguido, pois é justamente a atuação estatal, agora também por meio da regulação, que garante e efetiva o Constitucionalismo Democrático no contexto da tensa relação entre Estado e economia.

Assim sendo, as críticas (que são diversas e fundadas) sobre a atividade regulatória devem persistir, porém sob uma perspectiva de aperfeiçoamento, e não de negação ou extirpação desse mecanismo interventista do ordenamento jurídico pátrio. 
É nesse contexto que se insere a Análise de Impacto Regulatório, como tentativa de racionalização da atividade regulatória, através de aferições acerca da influência da regulação sobre a atuação dos agentes privados.

\subsection{A ORIGEM E OS FUNDAMENTOS DA ANÁLISE DE IMPACTO REGULATÓRIO}

A Análise de Impacto Regulatório tem origem no final do século $X X$, em especial em suas últimas três décadas, tendo os países anglo-saxões como berço implementador de tal mecanismo de racionalização da intervenção estatal no domínio privado.

Assim sendo, deve-se contextualizar o período do pós Segunda Guerra Mundial, que erigiu um sistema capitalista centrado na elevada atuação do Estado no setor econômico, tendo em vista a necessidade de grandes investimentos e aportes financeiros para o desenvolvimento da economia naquele contexto.

No entanto, o final da Guerra Fria e a efetivação da globalização em todo o contexto político global trouxeram mudanças também na relação entre Estado e economia. No pêndulo histórico retoma-se a tentativa de diminuição das interferências estatais no setor econômico, construindo-se, assim, contexto de privatizações e maior liberdade à atuação dos entes privados.

Todavia, conforme acima já exposto, o Estado não se afastou por completo do setor econômico, e nem assim deve proceder. A regulação surge justamente nesse contexto de protagonismo dos atores privados na produção econômica, passando o ente estatal a atuar de maneira indireta, por meio do estabelecimento de normas regulatórias.

Todo esse período histórico já delineado acima serve também de substrato para o surgimento da Análise de Impacto Regulatório. Suas primeiras manifestações remontam à década de 1970, sendo institucionalizado nos anos de 1990 (SALGADO, 2010, p. 10-11), com destaque para os Estados Unidos de Ronald Regan e a Inglaterra de Margaret Thatcher.

A efetivação de fato da Análise de Impacto Regulatório se deu por meio da Organização para a Cooperação e Desenvolvimento Econômico, em 1997, através do guia de boas práticas a ser seguido para a implementação de tal Análise (SALGADO, 2010, p. 9): garantir o comprometimento político com a AIR; alocar responsabilidades 
cuidadosamente para o cumprimento das etapas da AIR; treinar os reguladores; utilizar um método analítico consistente, porém flexível; desenvolver e implementar estratégias de coleta de dados; concentrar esforços em objetivos precisos; integrar a AIR com os processos de elaboração de políticas, dando início o mais cedo possível ao processo de tomada de decisão; conferir publicidade aos resultados; envolver o público extensivamente; e aplicar a AIR tanto a novas propostas regulatórias como à revisão de regulação existente.

Como se vê, a preocupação das Análise de Impacto Regulatório é constatar os efeitos que a atividade regulatória do Estado sobre a economia geram. Por isso, autores remontam ao utilitarismo de Bentham como precursor ideológico (SALGADO, 2010, p. 10) desse instrumento de racionalização de intervenção estatal.

Cabe ressaltar que o movimento de criação da Análise de Impacto Regulatório indica uma virada na concepção da atuação da Administração Pública: de meramente burocrática, para eminentemente gerencial (OLIVEIRA, 2011), voltando-se à obtenção de resultados (eficiência) e caracterizada pela descentralização administrativa.

Outra mutação que se pode constatar é com relação ao Direito Administrativo. Nesse mesmo contexto ora narrado, tal seara jurídica, antes centrada em atos administrativos concretos e regulamentares e tendo o processo administrativo como mero acessório de atuação, passa agora a ser centrada justamente no processo administrativo, compreendido não mais como mecanismo de defesa do particular, mas também como instrumento de obtenção e reconhecimento de direitos em uma perspectiva ampla, bem como meio de colaboração entre Administração e particular na elaboração normativa (MOREIRA, 2009, p. 104).

Desse modo, podem-se compreender as origens históricas Análise de Impacto Regulatório, datada do final do século $X X$ no âmbito da OCDE, estando também interligada com as notórias mutações no Direito Administrativo.

\subsection{A PROCEDIMENTALIZAÇÃO DA ANÁLISE DE IMPACTO REGULATÓRIO}

A Análise de Impacto Regulatório, a partir da edição das Leis Federais $n$. 13.848/2019 (Lei das Agências Reguladoras) e 13.874/2019 (Lei da Liberdade Econômica), passou a ser instrumento legalmente previsto no ordenamento jurídico brasileiro, devendo ser adotada e institucionalizada nos processos decisórios das Agências Reguladoras, bem como nas hipóteses de realização de regulação por 
qualquer ente normativo estatal.

Dessa maneira, com as mencionadas novidades legislativas, a Análise de Impacto Regulatório se torna instrumento de racionalização a ser obrigatoriamente efetivada e procedimentalizada nas mencionadas hipóteses legais.

Nesse sentido, a Análise de Impacto Regulatório pode ser procedimentalizada de diversas formas, originando na doutrina especializada classificações a esse respeito (OLIVEIRA, 2011). Assim, com relação ao conteúdo de sua metodologia, pode ser Análise Custo-Benefício - ACB, considerando todos os custos e todos os benefícios envolvidos na regulação por ela proposta, inclusive aqueles que não podem ser auferidos economicamente, ou Análise do Custo-Efetividade - ACE, por meio do qual há definição prévia das metas regulatórias que devem ser implementadas pela forma menos custosa.

Quando o foco se voltar para a abrangência da Análise, esta pode ser geral, na medida em que os impactos que da regulação afetarão toda a sociedade e a economia, ou parcial, quando os referidos impactos atingirem determinado setor da economia ou da sociedade.

Por fim, cabe mencionar também a classificação a respeito da obrigatoriedade, sendo a Análise de Impacto Regulatório obrigatória, nas hipóteses de ser uma condição de validade para a decisão regulatória, ou facultativa, se não for imposta pela legislação, cabendo ao regulador a opção discricionária para sua implementação.

Com relação ao momento de se realizar a Análise de Impacto Regulatório, esta poderá se dar em momento anterior à regulação, oferecendo múltiplas alternativas ao ente regulador, bem como análises a respeito dos potenciais custos e benefícios e avaliações dos impactos que podem advir dos atos regulatórios normativos (GUERRA, 2012, p. 31); ou em momento concomitante, quando se voltar para a análise crítica de regulação já em execução, propondo melhorias e reformas, se necessárias, às normas regulatórias.

De todo modo, a doutrina especializada (SALGADO, 2010, p. 12-14) indica que os princípios da transparência, da governança, da proporcionalidade, da economicidade e da eficiência devem ser atendidos na realização da Análise de Impacto Regulatório, de maneira que se torne concreta, real e efetiva o estudo crítico realizado.

Assim, a referida Análise será materializada por meio de relatório específico, tendo como elementos essenciais (SOUSA, 2012): sumário executivo objetivo, 
identificação do problema regulatório, dos atores afetados, da base legal que ampara a regulação, a definição dos objetivos que se pretenda alcançar, a descrição de possíveis alternativas, a exposição dos possíveis impactos, a comparação das alternativas consideradas, a descrição da estratégia para implementação da alternativa sugerida, as considerações referentes à informação e a assinatura e nome completo dos responsáveis.

Por fim, interessante constatar outros métodos analíticos de Análise de Impacto Regulatório, aplicados em casos específicos que demandam certas peculiaridades (SALGADO, 2010, p. 15-17). Assim, podem ser citados: (i) Costeffectivness analysis, consistente em análise comparativa dos custos entre regulações que geram benéficos iguais ou semelhantes, precedendo o desenvolvimento de uma Análise de Impacto Regulatório fundada em Análise de Custo-Benefício; e (ii) teste de limiar, utilizado para dispensar a análise ou reduzir a extensão desta, para casos em que a regulação gera impactos relativamente pequenos, ou quando não há alternativa política apropriada à regulação.

Ante o exposto, constata-se que a Análise de Impacto Regulatório pode assumir diversas modalidades, sendo a mais usual a Análise Custo-Benefício, o que, todavia, não impede que outras formas sejam estabelecidas, devendo-se, preponderar, no caso, o mecanismo mais efetivo para realização de análise crítica e fundamentada do fenômeno sob observação.

\subsection{OS DESAFIOS A SEREM ENFRENTADOS PARA A INSTITUCIONALIZAÇÃO DA ANÁLISE DE IMPACTO REGULATÓRIO}

Por fim, cabe ressaltar os desafios a serem enfrentados para a institucionalização da Análise de Impacto Regulatório no Brasil, em especial a partir das alterações legislativas advindas com as Leis Federais n. 13.848/2019 e 13.874/2019.

Buscando sintetizar e aprimorar aspectos principais e de maior relevo para essa temática, a doutrina indica alguns pontos prioritários para a institucionalização da Análise de Impacto Regulatório no país (OLIVEIRA, 2011), tais como a edição de normas legais e regulamentares que estabeleçam sua obrigatoriedade; a padronização mínima; a agenda regulatória, por meio da definição dos objetivos regulatórios que se buscam alcançar, respeitando, naturalmente, as normas financeiras previstas nas leis 
orçamentárias; participação popular através do reforço da previsão e da efetivação dos instrumentos de participação popular, como as audiências e as consultas públicas; e transparência, efetivada por meio de ampla divulgação dos atos necessários a sua implementação.

A respeito do incremento e da maior participação popular, deve-se ressaltar a importância da realização das consultas e audiências públicas, como mecanismo de legitimidade para a regulação que será imposta ou que já se encontra em execução.

Ademais, tais mecanismos de participação popular indicam também uma forma de se garantir a maior segurança jurídica na regulação, diante das constantes novidades advindas do seio social, bem como de seu contínuo aumento de complexidade, necessitando de progressiva mutação regulatória, de modo que esta persista atual e de acordo com os anseios e necessidades sociais (MOREIRA, 2009, p. 111).

\section{A DEVIDA COMPREENSÃO DA ATIVIDADE REGULATÓRIA NO CONTEXTO DO CONSTITUCIONALISMO DEMOCRÁTICO}

A relação entre Estado e economia ao longo do século XXI vem manifestandose com tensionamento cada vez mais elevado, em especial no contexto das transformações na ordem social e econômica e regulação. A despeito da crescente força adquirida pelo discurso neoliberal, não se pode relegar as conquistas do Estado Democrático de Direito. Dessa forma, o tensionamento entre Estado e economia deve se processar na esfera do Constitucionalismo Democrático, sendo a função regulatória a alternativa sintética obtida através das experiências dialéticas vivenciadas nos últimos três séculos entre Estado Liberal e Estado Social de Direito.

Nesse sentido, afirmar a regulação, que se difere na essência da burocratização, consiste justamente em efetivar o jurídico como alternativa para preservação do sistema constitucional democrático vigente. Ceder aos incursos neoliberais, nesse contexto, apresenta-se, na prática, por meio da massiva busca da negação do Direito, sob a ilusória imagem de autossuficiência do mercado. Assim sendo, a tênue distinção entre desregulação e desburocratização deve ser realçada de modo que não se permita com que a ofensiva neoliberal sepulte as bases institucionais em que se fundamenta o Estado Democrático de Direito.

Nesse contexto, cabe retomar sumariamente a evolução histórica vivenciada 
do sistema capitalista até os dias atuais. Tal modo de produção fundamentou-se, primeiramente, na atuação livre do mercado e de baixa interferência estatal ao longo dos séculos XVIII e XIX, no período conhecido como Estado Liberal de Direito. Ocorre que as crises experimentadas pelo sistema, bem como a necessidade de aporte financeiro estatal na economia (MARQUES NETO, 2002, p. 102) levou, ao longo do século $X X$, ao que se chama de Estado Social de Direito, marcado pela intensa intervenção estatal. Dessa relação dialética entre Estado Liberal, de baixo intervencionismo estatal (tese), e Estado Social, de cunho intervencionista (antítese), emerge, no final do século XX, o Estado Democrático de Direito, no qual a relação entre Estado e economia se dá de maneira mais complexa, com destaque para a função regulatória estatal.

Dessa forma, pode-se extrair do Estado de Direito três elementos que the servem de substrato (SALGADO, 1998, p. 41), quais sejam, (i) o ontológico, no caso, a legitimidade democrática, (ii) o lógico, materializado pela legalidade e pelo Direito, e (iii) o teleológico, que é a busca pela justiça. Assim, compreende-se ser o Estado de Direito um Estado ético mediatizado, na medida em que almeja a justiça mediada pelo Direito.

Mantendo essa característica, o Estado Democrático de Direito apresenta novas acepções, contextualizadas com as novas complexidades do mundo pósModerno. No caso, os direitos fundamentais manifestam-se como os valores éticos buscados pelo Estado por meio da mediação do Direito (COELHO, 2012, p. 297). Portanto, o Constitucionalismo Democrático garante que os direitos fundamentais sejam respeitados pelo sistema capitalista vigente.

Com relação à ordem econômica, sua relação com o Estado, no contexto do Constitucionalismo Democrático, se dará de maneira complexa (MOREIRA, 2014, p. 125): (i) gestão pública de atividade econômicas, (ii) o direito de ordenação social (fiscalização), (iii) a edição de normas jurídicas voltadas para a conduta do agente econômico e (iv) o planejamento estatal na economia, nos termos dos artigos 170 a 174, CF. Como regulador do mercado, o Estado não mais apresenta a direção pura e exclusiva dos processos econômicos, assumindo também a direção técnica e social através de entes independentes (MOREIRA NETO, 2005).

Acerca dos últimos dois pontos apresentados acima, se extrai a função regulatória do Estado na economia. A regulação implica uma nova concepção estatal (CHEVALLIER, 2009, p. 72), pressupondo que o sistema econômico não é capaz de 
atingir, por si só, o equilíbrio, havendo a necessidade, assim, da mediação do Estado, por meio do Direito, para o alcançar.

Assim sendo, situado o atual momento histórico do sistema capitalista e do Estado de Direito, é possível compreender que os incursos tidos como neoliberais, como visto pela Medida Provisória n. 881/2019, convertida na Lei Federal n. 13.874/2019, em especial as limitações gerais previstas no artigo $4^{\circ}$ e a exigência de Análise de Impacto Regulatório pelo artigo $5^{\circ}$, fundado no conceito indeterminado de razoabilidade do impacto econômico, buscam, em suma, limitar a atuação da atividade regulatória.

Evidentemente, estabelecer limites de atuação para qualquer esfera de poder é, a priori, coerente e contextualizado com o Estado de Direito, que busca, justamente, por meio da definição de competências, definir limites para o desempenho de qualquer centro de poder.

Ademais, os mencionados dispositivos da Lei Federal n. 13.874/2019, conforme já analisados acima, consistem em diretrizes que, em tese, se mostram adequadas e coerentes com o ordenamento jurídico pátrio.

No entanto, o que se deve ponderar são os excessos que podem ocorrer, em especial quando se constata a existência de conceitos notoriamente indeterminados servindo como vetor de limitação da atividade regulatória.

Dessa forma, conforme se constata no texto da referida Lei Federal, emergem possibilidades interpretativas nas quais se experimentará autêntica construção de um Estado que nega o Direito, na medida em que busca coibir o poder de regulação estatal, componente do elemento lógico do Constitucionalismo Democrático para efetivação dos direitos fundamentais.

Isso porque, em suma, evidenciam-se três aspectos que afrontam o Estado Democrático de Direito. Em primeiro lugar, o artigo $4^{\circ}$ como um todo, intitulado de "Garantias de livre iniciativa", busca restringir o poder de regulação estatal por meio de conceitos abertos e indeterminados, na busca ilusória de maior eficiência, diminuição de custos de transação e consagração da liberdade econômica. Tal postura evidencia tratar-se de política pública de governo desassociada das políticas de Estado, tendo em vista que estas, de caráter perene, voltam-se para proteção dos direitos fundamentais e da Constituição (AITH, 2006, p. 232).

Além disso, constata-se a ausência de referências aos demais princípios que regem a ordem econômica brasileira, consistindo a lei em comento proteção única e 
exclusiva da liberdade econômica / livre iniciativa (nos termos do art. 170, CF: livre concorrência e propriedade privada). Por fim, a ausência de legitimidade ontológica (democrática) salta aos olhos, na medida em que um tema de enorme relevância para o Estado brasileiro foi tratado inicialmente de maneira unilateral pelo Poder Executivo por meio de Medida Provisória, quando o debate no Poder Legislativo desde o seu primórdio se mostrava de fundamental importância para o aprofundamento nas análises.

Dessa forma, deve-se agir com a devida cautela no momento de aplicação da referida lei, de modo que esta não ocorra de forma descontextualizada do Constitucionalismo Democrático. Isso porque pode-se constatar eventual negação do elemento lógico do Estado (SALGADO, 1998, p. 41), tendo em vista a desconstituição da base jurídica institucional. Ainda, observa-se uma tentativa de retomada a um Estado paternalista, caracterizado por exclusivamente prestar serviços e punir seus súditos (MOREIRA, 2014, p. 108), negando a possibilidade de atuação do Estado ao lado do domínio econômico, por meio da regulação exercida por aquele sobre este.

Assim sendo, a relação Estado e economia deve se dar no contexto do Constitucionalismo Democrático. Isso significa, em suma, que a disciplina constitucional deve servir de guia para tal relação, afirmando, assim, o elemento lógico do Estado de Direito, isto é, o campo jurídico, que o neoliberalismo tanto busca anular. Desse modo, o elemento justiça, sobreprincípio do Constitucionalismo atual, na medida em que consiste em vetor do Estado Ético mediatizado pelo Direito (SALGADO, 1998, p. 41), deve ser o guia na aplicação dos demais conceitos: liberdade econômica e eficiência, ambos princípios constitucionais, e os custos de transação (artigo $4^{\circ}$, V, Lei Federal n. 13.874/2019), erigido agora como diretriz infraconstitucional / legal. Nesse contexto, cabe acentuar três conceitos primordiais nessa temática: o de liberdade econômica, o da eficiência e o de custos de transação.

Acerca da liberdade econômica, princípio constitucional estatuído como livre concorrência (art. 170, IV, CF), não se pode olvidar da necessidade de atuação estatal por meio de políticas públicas inclusivas (SCHMIDT, 2008, p. 2313), tendo em vista a formação histórica brasileira fundada na concentração de riqueza e exclusão social (FURTADO, 2016, p. 84), sob pena de restar impossibilitada a implementação de qualquer sistema econômico realmente livre.

Com relação à eficiência, princípio constitucional previsto no art. 37, caput, deve-se apontar que o caminho não é a negação da regulação para se alcança-la, 
como pretende o neoliberalismo, mas sim a elaboração de instrumentos que possam criticar e avançar no campo regulatório brasileiro. Cita-se, como exemplo, a Análise de Impacto Regulatório, que consiste em metodologia para avaliação das consequências atuais e futuras da regulação, por meio de planejamento e participação social (OLIVEIRA, 2011).

Por fim, os custos de transação, que consistem nos gastos que o agente privado terá na realização de operações negociais de direitos de propriedade (PEREIRA, MALAQUIAS e RIBEIRO, 2010, p. 193), por meio da Lei Federal $\mathrm{n}$. 13.874/2019, é erigida agora à diretriz infraconstitucional / legal, como elemento a ser evitado na atuação da Administração Pública.

Dentro dessa relação cabe ressaltar a importância da regulação, justamente por ser tal instrumento que garantirá a presença do jurídico e do Estado na atuação do setor econômico. De fato, não se nega que existam problemas regulatórios a serem tratados, conforme já abordado acima. Ocorre que isso não pode ser confundidos com burocratização. Assim, a desburocratização visa diminuir os custos de transação, respeitando a legalidade, enquanto a desregulamentação é caminho pernicioso, na medida em que busca eliminar o elemento lógico do Estado Democrático.

Ainda, tal relação deve se processar com respeito ao texto constitucional, sob pena de consagração da ineficácia das normas dispostas na Constituição, fenômeno tido como constitucionalismo simbólico (NAVES, 2011). Além disso, deve-se ter consciência da formação histórica brasileira, fundada sobre instituições extrativistas (ACEMOGLU e ROBINSON, 2012), gerando desigualdades que necessitam de atuação ativa do Estado.

Dessa maneira, a tensão entre Estado e economia deverá se processar no bojo do Constitucionalismo Democrático, sendo a categoria justiça, vetor ético do Estado Democrático, o sobreprincípio que delimitará a interpretação e aplicação dos princípios constitucionais da liberdade econômica e da eficiência, que, por sua vez, delimitarão também o campo de atuação da diretriz que busca diminuir os custos de transação.

\section{CONSIDERAÇÕES FINAIS}

O presente estudo logrou êxito quanto ao problema proposto, tendo encontrado, o caminho que deve ser seguido pelo Estado brasileiro nessa tensa 
relação entre Estado e economia no contexto do Constitucionalismo Democrático.

A regulação, fenômeno recente no contexto mundial, emerge como uma alternativa que tende a ser eficiente em seus propósitos, na medida em que abre espaço para a atuação dos agentes privados no aspecto econômico, mas sem que isso negue ou afaste a presença do Estado nesse cenário.

Buscando trazer maiores efetividade para a atividade regulatória no Brasil, devem ser discutidos e elaborados projetos que reduzam os efeitos deletérios que podem advir dessa modalidade de intervenção estatal na economia. Assim, a Análise de Impacto Regulatório surge como eficaz instrumento para se aferir os efeitos da regulação sobre o setor regulado, devendo, portanto, ser cada vez mais aprimorado e utilizado no Estado brasileiro. 


\section{REFERÊNCIAS}

ACEMOGLU, Daron; ROBINSON, James. Por que as nações fracassam - A origem do poder, da prosperidade e da pobreza. Rio de Janeiro, Elsevier, 2012.

AITH, Fernando. Políticas públicas de Estado e de governo: instrumentos de consolidação do Estado Democrático de Direito e de promoção e proteção dos direitos humanos. In BUCCI, Maria Paula Dallari (org.). Políticas Públicas - Reflexões sobre o conceito jurídico. São Paulo: Saraiva, 2006, p. 217-245.

BANDEIRA DE MELLO, Celso Antônio. Lei e Regulamento. A chamada "reserva de lei". As delegações legislativas disfarçadas in Revista Trimestral de Direito Público, vol. 49-50. São Paulo: Malheiros, 2005.

BRASIL. Constituição Federal, de 05 de outubro de 1988. Diário Oficial da República Federativa do Brasil, 05 de outubro de 1988.

BRASIL. Lei Federal n. 13.848, de 26 de junho de 2019. Diário Oficial da República Federativa do Brasil, 25 de junho de 2019.

BRASIL. Lei Federal n. 13.874, de 20 de setembro de 2019. Diário Oficial da República Federativa do Brasil, 20 de setembro de 2019.

CHEVALLIER, Jacques. O Estado Pós-Moderno. Trad. Marçal Justen Filho. Belo Horizonte: Fórum, 2009 (p.59-98).

COELHO, Saulo de Oliveira. Reconhecimento, Experiência e Historicidade: considerações para uma compreensão dos Direitos Humano-Fundamentais como (in)variáveis principiológicas do Direito nas sociedades democráticas contemporâneas. In: SOBREIA; FARIAS; OLIVEIRA JR. Filosofia do Direito. Florianópolis:

Conpedi/FUNJAB, 2012, p. 289-310

COUTINHO, Diogo Rosenthal. A MP da Liberdade Econômica e a mão invisível. JOTA Info on-line, 28 mai. 2019. Disponível em:

$<$ https://www.jota.info/paywall?redirect to=//www.jota.info/tributos-eempresas/regulacao/a-utopia-do-laissez-faire-28052019\# ftn4>. Acesso em: 20 mai. 2020.

FRAZÃO, Ana de Oliveira. MP da Liberdade Econômica: temos razões para comemorar ou para nos preocupar?. JOTA Info on-line, 14 ago. 2019. Disponível em: <https://www.jota.info/paywall?redirect to=//www.jota.info/opiniao-eanalise/colunas/constituicao-empresa-e-mercado/mp-da-liberdade-economica-temosrazoes-para-comemorar-ou-para-nos-preocupar-14082019> Acesso em: 20 mai. 2020.

FURTADO, Celso. Formação Econômica do Brasil. 34 ed. São Paulo, Companhia das Letras, 2016.

GRAU, Eros Roberto. O Direito Posto e o Direito Pressuposto, $8^{a}$ ed. São Paulo: Malheiros, 2011 (p.167-190). 
GUERRA, Sérgio; SAMPAIO, Patricia. Análise de Impacto Regulatório, Revista Justiça \& Cidadania, volume 145, 2012, páginas 30 a 33.

GUERRA, Sérgio. Normatização por entidades reguladoras independentes: uma contribuição para o desafio da tecnicidade. In: GUERRA, Sérgio (org). Temas de Direito Regulatório. Rio de Janeiro: Freitas Bastos, 2004, p.1-41.

GUERRA, Sérgio. Regulação estatal sob a ótica da organização administrativa brasileira. Revista de Direito Público da Economia, v. 1, p. 229-248, 2013.

MAJONE, G. As Transformações do Estado Regulador. Revista de Direito Administrativo, v. 262, 2013, p. 11-43.

MARQUES NETO, Floriano de Azevedo. Finalidades e Fundamentos da Moderna Regulação Econômica, Fórum Administrativo, volume 100, 2009, páginas 85 a 93.

MARQUES NETO, Floriano Peixoto de Azevedo. Regulação estatal e interesses públicos. São Paulo: Malheiros, 2002. (p.100-143)

MOREIRA, Egon Bockmann. Agências Administrativas, Contratos de Serviço Público e Mutabilidade Regulatória, Revista de Direito Público da Economia, volume 25, 2009, páginas 101 a 117.

MOREIRA, Egon Bockmann; CAGGIANO, Heloisa Conrado. O poder normativo das agências reguladoras na jurisprudência do STF: mutação constitucional do princípio da legalidade? Revista de Direito Público da Economia - RDPE, Belo Horizonte, ano 11, n. 43, jul./set. 2013.

MOREIRA, Egon Bockmann. Passado, presente e futuro da regulação econômica no Brasil. Revista de Direito Público da Economia - RDPE, Belo Horizonte, ano 11, n. 44, p. 87-118, out./dez. 2013

MOREIRA, Egon Bockmann. Qual é o Futuro do Direito da Regulação no Brasil? In: Carlos Ari Sundfeld; André Rosilho (Organização). Direito da Regulação e Políticas Públicas, $1^{\mathrm{a}}$ edição, São Paulo, Malheiros Editores, volume 1, 2014, páginas 107 a 139.

MOREIRA NETO, Diogo de Figueiredo. Mutações do Direito Administrativo, $3^{a}$ ed. Rio de Janeiro: Renovar, 2007 (p.7-36).

MOREIRA NETO, Diogo de Figueiredo. O Novo Papel do Estado na Economia. Revista de Direito Público da Economia - RDPE Belo Horizonte, n. 11, ano 3 Julho / Setembro 2005

NEVES, Marcelo. A constituição Simbólica. $3^{a}$ edição. São Paulo: Editora WMF Martins Fontes, 2011. Capítulo I

OLIVEIRA, Rafael Carvalho Rezende. Governança e Análise de Impacto Regulatório. Revista de Direito Público da Economia - RDPE, Belo Horizonte, ano 9, n. 36, out./dez. 2011 
PEREIRA, Carlos Antônio; MALAQUIAS, Rodrigo Fernandes; RIBEIRO, Kárem Cristina de Sousa. Quando custos de produção e custos de transação são mutuamente exclusivos?. Pesquisa \& Debate. Revista do Programa de Estudos Pós-Graduados em Economia Política., [S.I.], v. 21, n. 2(38), nov. 2011. ISSN 1806-9029. Disponível em: < https://revistas.pucsp.br/rpe/article/view/7394 >. Acesso em: 20 mai. 2020.

PEREIRA NETO, Caio Mário da Silva; LANCIERI, Filippo Maria; ADAMI, Mateus Piva. O Diálogo Institucional das Agências Reguladoras com os Poderes Executivo, Legislativo e Judiciário: Uma Proposta de Sistematização. SUNDFELD, Carlos Ari; ROSILHO, André Janjácomo. Direito da Regulação e Políticas Públicas, São Paulo, Malheiros, 2014

PIKETTY, Thomas. O Capital no Século XXI. 1. ed. Rio de Janeiro: Intrínseca, 2014. $669 p$.

SALGADO, Joaquim Carlos. O Estado Ético e o Estado Poiético. Revista do Tribunal de Contas do Estado de Minas Gerais, Belo Horizonte, v. 27, n. 2, p. 37-68, abr./jun. 1998.

SALGADO, Lucia Helena. Agências Regulatórias na Experiência Brasileira: um panorama do atual desenho institucional in Texto para Discussão, vol. 941. Rio de Janeiro: IPEA, 2003.

SALGADO, Lucia Helena; BORGES, Eduardo Bizzo de Pinho. Análise de impacto regulatório: uma abordagem exploratória. in Texto para Discussão, vol. 1463. Brasília: IPEA, 2010.

SCHMIDT, João Pedro. Para entender as políticas públicas: aspectos conceituais e metodológicos. In: REIS, Jorge Renado; Leal, Rogério Gesta (orgs.). Direitos Sociais e políticas públicas: desafios contemporâneos. Santa Cruz do Sul: EDUNISC, 2008.

SOUSA, Renan Martins de. A Análise de Impacto Regulatório (AIR) e o papel do Tribunal de Contas da União na avaliação da regulação setorial. Revista do Tribunal de Contas da União, Brasília, n.123, jan/abr2012, p.102-123.

SILVA, Vírgílio Afonso. O Judiciário e as políticas públicas: entre transformação social e obstáculo à realização dos direitos sociais. In SOUZA NETO, Cláudio Pereira de e SARMENTO, Daniel. Direito Sociais: fundamentação, judicialização e direitos sociais em espécies. Rio de Janeiro: Lumen Juris, 2008, p. 587-599.

SUNDFELD, Carlos Ari. Direito Administrativo para Céticos. São Paulo: Malheiros, 2012. (p.231-280)

SUNDFELD, Carlos Ari. Meu depoimento e avaliação sobre a Lei Geral de Telecomunicações. Revista de Direito de Informática e Telecomunicações - RDIT, Belo Horizonte, ano 2, n. 2, p. 55-84, jan./jun. 2007.

SUNSTEIN, Cass R. As funções das normas reguladoras. Revista de Direito Público da Economia - RDPE, Belo Horizonte, ano 1, n. 3, p. 33-65, jul./set. 2003. 
Recebido em 25/05/2020

Aprovado em 03/12/2020

Received in 25/05/2020

Approved in 03/12/2020 